Article

\title{
Synthesis of ZSM-5 Zeolite Using Coal Fly Ash as an Additive for the Methanol to Propylene (MTP) Reaction
}

\author{
Rui Feng *, Kening Chen, Xinlong Yan, Xiaoyan Hu, Yixin Zhang and Jianjun Wu
}

Key Laboratory of Coal Processing and Efficient Utilization (Ministry of Education), School of Chemical Engineering, China University of Mining \& Technology, Xuzhou 221116, China; cumtkening@163.com (K.C.); yx119832002@163.com (X.Y.); hxy_cumt@163.com (X.H.); zhangyixinchina@126.com (Y.Z.); jjuw@163.com (J.W.)

* Correspondence: fengrui@cumt.edu.cn; Tel.: +86-135-8538-9534

Received: 4 September 2019; Accepted: 18 September 2019; Published: 22 September 2019

\begin{abstract}
Using ZSM-5 zeolites as catalysts for the methanol to propylene (MTP) reaction is being widely investigated and has been industrially applied. In this study, pure ZSM- 5 zeolite was successfully synthesized by a direct hydrothermal method using the fly ash of coal gasification as an additional raw material. Various analysis methods such as X-ray diffraction, $\mathrm{N}_{2}$ sorption, scanning electron microscopy, and infrared spectroscopy, were employed to characterize the physicochemical properties of parent and modified zeolites. Then, the prepared ZSM- 5 catalysts were tested in the MTP reaction. The results showed that pure ZSM- 5 could be directly synthesized in the optimized conditions using fly ash as additional silicon and aluminum sources, and those ZSM- 5 catalysts turned out to be candidate catalysts for the MTP reaction. Whereas their catalytic lifetimes were not good enough due to the strong acid sites and needed improving.
\end{abstract}

Keywords: ZSM-5; coal fly ash; alkaline treatment; methanol to propylene

\section{Introduction}

A large amount of fly ash has been generated from coal-based industries such as coal gasification and thermal power plants [1,2]. Generally, these solid wastes were disposed by landfill and caused environmental problems. Furthermore, it may soon be expensive to dispose of the fly ash owing to stricter legislative requirements. As a consequence, the reuse of coal fly ash has been pressing and attractive in the case of its important economic and environmental implications. Recently, researchers have tried to use fly ash as the soil amendment, adsorbents, and building materials [3]. Considering its rich in silicon and aluminum sources, an alternative usage of fly ash is to synthesize the value-added zeolites.

Zeolites are crystals consisting of high specific surface area and extensively micropore structure developed by framework silicon and aluminum oxygen tetrahedrons, having potential applications in the fields of petrochemical reactions [4,5], water purification, the purification of gas [6], and catalytic reactions of green chemistry, etc. [7-11]. Amongst, ZSM-5 zeolite is a three-dimensional crystalline aluminosilicate with silicon and aluminum tetrahedral that form frameworks with a relatively high $\mathrm{SiO}_{2} / \mathrm{Al}_{2} \mathrm{O}_{3}$ ratio $[12,13]$. They have been successfully used in the fields of oil refining, environmental protection, and methanol to light olefins due its adjustable surface acidity, micropore structure, and hydrothermal stability. Nowadays, it is still of vital importance to reduce costs to synthesize this zeolite with inexpensive silica and aluminum raw materials [14].

In the last decade, many researchers have successfully employed coal-based fly ash to synthesize different zeolites using different types of methods, such as hydrothermal, hydrothermal with fusion pretreatment, microwave and ultrasound techniques $[15,16]$. So far, sodalite, faujasite, P zeolite, A-type 
zeolite, and ZSM-5 zeolite have been synthesized in many studies [15,17,18]. For instance, Ojumu et al. [15] synthesized a pure phase zeolite A from coal fly ash using ultrasonic treatment. Cardoso et al. [17] synthesized zeolites $4 \mathrm{~A}$ and Na-P1 by two different routes using coal fly ash for treating wastewater. Belviso [1] synthesized Y zeolite from fly ash by sonication and the conventional hydrothermal method. Soongprasit et al. [19] synthesized ZSM-5 zeolite from fly ash by the alkali hydrothermal method, however, the ZSM-5 zeolite was impure associated with wairakite. Vichaphund et al. [20] prepared ZSM-5 zeolite from fly ash, which was also pretreated by hydrothermal alkaline fusion.

In general, fly ash is a combusted by-product derived from coal burning or gasification. It consists primarily of an amorphous aluminosilicate glass. Thus, in the above studies, fly ash was usually pretreated by dissolution of its crystalline and amorphous phases in alkaline such as $\mathrm{NaOH}$ and $\mathrm{KOH}$ in order to make the $\mathrm{Si}$ and $\mathrm{Al}$ available for the formation of zeolite framework during the crystallization, as summarized in previous literature [20]. Though several works were widely studied on the synthesis of ZSM-5 from fly ash, there have been few reports focusing on ZSM-5 derived from ash without alkali fusion pretreatment [15].

The aim of this work is to synthesize ZSM- 5 catalysts by the conventional hydrothermal method using fly ash as an additive without the alkali fusion step. The structural characterization data are discussed alongside the catalytic performance of the zeolite materials in the methanol to propylene (MTP) reaction.

\section{Results and Discussion}

\subsection{Fly Ash Pretreatment}

The chemical composition of as-received fly ash is shown in Table 1. It shows that the fly ash was mainly composed of silicon oxide, alumina, and unreacted residual carbon. Other impurities such as iron oxide, calcium oxide, and potassium oxide, were unfavorable in the synthesis of ZSM-5 zeolite and should be removed. Here, nitric acid with fixed concentration of $2 \mathrm{~mol} / \mathrm{L}$ was used for washing the raw fly ash. The weight loss of fly ash with increasing the liquid-to-solid (L/S) ratio is displayed in Figure 1. It shows that with increasing the L/S ratio, the mass of residual solid fly ash gradually decreased and remained unchanged after the $\mathrm{L} / \mathrm{S}$ ratio up to 10 . The chemical composition of acid washed fly ash at $\mathrm{L} / \mathrm{S}=10$ is shown in Table 1 . It shows that after acid washing, part of the soluble metal oxides such as alumina, ferric oxide, calcium oxide, and potassium oxide were removed. By contrast, silicon oxide and residual were inert in the pretreatment of acid solution, leading to the increase of silicon to alumina molar ratio.

Table 1. Chemical compositions of fly ash derived from the X-ray fluorescence (XRF) analysis and element analysis on the basis of mass weight (wt\%).

\begin{tabular}{cccccccc}
\hline Sample & $\mathrm{SiO}_{\mathbf{2}}$ & $\mathrm{Al}_{\mathbf{2}} \mathbf{O}_{\mathbf{3}}$ & $\mathrm{Fe}_{\mathbf{2}} \mathrm{O}_{\mathbf{3}}$ & $\mathbf{C a O}$ & $\mathbf{K}_{\mathbf{2}} \mathbf{O}$ & $\begin{array}{c}\text { Residual } \\
\text { Carbon }\end{array}$ & $\begin{array}{c}\mathrm{SiO}_{2} / \mathrm{Al}_{\mathbf{2}} \mathbf{O}_{3} \\
\text { Molar Ratio }\end{array}$ \\
\hline As received fly ash & 36.74 & 21.91 & 5.47 & 5.68 & 1.32 & 28.51 & 2.96 \\
After acid washing & 44.98 & 10.05 & 2.34 & 2.40 & 0.70 & 39.64 & 7.91 \\
\hline
\end{tabular}

The XRD patterns and SEM images of the as-received fly ash and acid washed once at $\mathrm{L} / \mathrm{S}=10$ are displayed in Figures 2 and 3, respectively. The XRD patterns in Figure 2 show that there were no obvious crystalline phases observed in the fly ash samples before and after acid washing. The amorphous fly ash was composed of globular glass beads with particle size below $2 \mu \mathrm{m}$, as shown in Figure 3. These glass beads with smooth surface were formed by coal gangue at high temperature around $1300{ }^{\circ} \mathrm{C}$ in the gasification furnace [21,22]. The small porous materials marked with yellow arrow in Figure $3 \mathrm{~b}$ was detected by a single point EDX analysis to be the unremoved carbon. The morphology of acid washed fly ash in Figure $3 \mathrm{~d}$ remained basically unchanged compared to as-received fly ash. Considering the elemental change in Table 2, it indicated that only a small amount of metal oxides on the surface of those 
glass beads, such as ferric oxide, calcium oxide, and potassium oxide, was removed after acid washing, while the residual metal oxides existing inside the glass beads could not be removed.

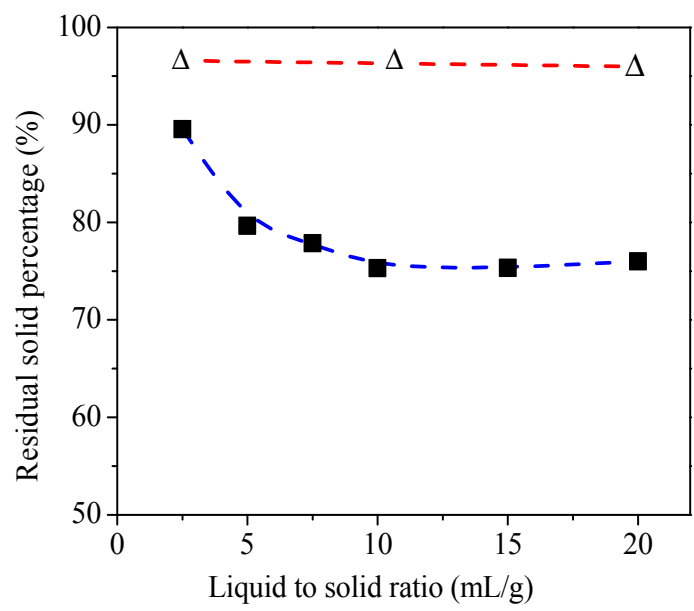

Figure 1. Weight loss of fly ash by nitric acid washing (the blue dash line) and the blank test by water washing (the red dash line).

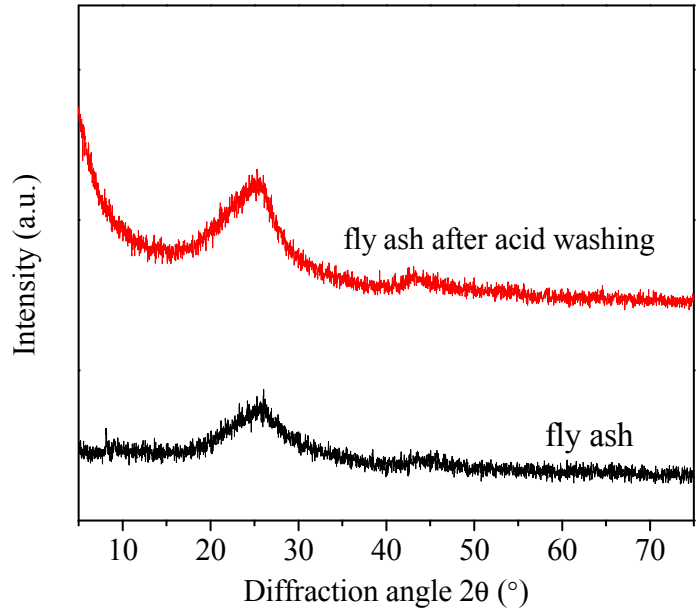

Figure 2. XRD patterns of fly ash before and after nitric acid washing.

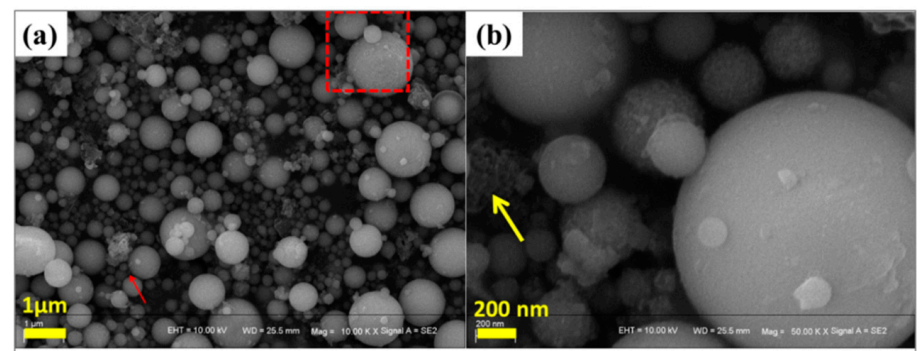

(c)

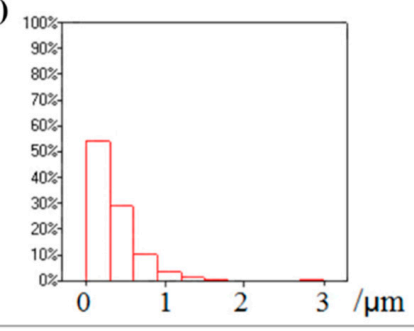

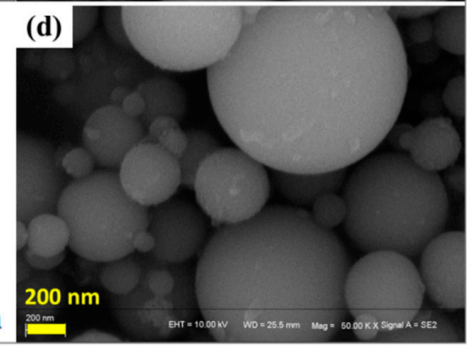

Figure 3. SEM images of the as-received fly ash (a) and its partial enlarged drawing of red dotted box (b) and its particle size distribution (c); (d) is the image of acid washed fly ash. 
Table 2. Preparation conditions of ZSM-5 zeolites and their physical properties.

\begin{tabular}{|c|c|c|c|c|c|c|c|c|c|c|c|}
\hline \multirow{2}{*}{ Item } & \multicolumn{3}{|c|}{ Preparation Conditions } & \multirow{2}{*}{$\mathrm{RC}^{\mathrm{a} / \%}$} & \multirow{2}{*}{$\begin{array}{c}\mathrm{SiO}_{2} / \mathrm{Al}_{2} \mathrm{O}_{3} \\
\text { Ratio }\end{array}$} & \multicolumn{3}{|c|}{$\mathrm{S}_{\mathrm{BET}} / \mathrm{m}^{2} \cdot \mathrm{g}^{-1}$} & \multicolumn{3}{|c|}{ Volume $/ \mathrm{cm}^{3} \cdot \mathrm{g}^{-1}$} \\
\hline & Fly Ash/g & TEOS/mol & $\begin{array}{c}\mathrm{Na}_{2} \mathrm{O} / \mathrm{SiO}_{2} \\
\text { Ratio }\end{array}$ & & & Total $^{\mathrm{c}}$ & $\mathrm{S}_{\text {meso }}$ & $\mathrm{S}_{\text {micro }}$ & Total $^{\mathrm{d}}$ & $\mathrm{V}_{\text {meso }}$ & $\mathrm{V}_{\text {micro }}$ \\
\hline Z5-S1 & 4.0 & 0.0 & 0.055 & - & 5.63 & 36.0 & 30.2 & 5.8 & 0.009 & 0.009 & - \\
\hline Z5-S2 & 4.0 & 0.017 & 0.055 & 31.81 & 9.54 & 145.1 & 44.5 & 100.6 & 0.010 & 0.001 & 0.010 \\
\hline Z5-S3 & 4.0 & 0.033 & 0.055 & 42.24 & 12.29 & 158.7 & 48.3 & 110.4 & 0.084 & 0.011 & 0.073 \\
\hline Z5-S4 & 4.0 & 0.067 & 0.055 & 52.94 & 17.42 & 217.1 & 66.8 & 150.3 & 0.071 & 0.002 & 0.069 \\
\hline Z5-S5 & 0.0 & 0.067 & 0.055 & 100.0 & 72.67 & 358.5 & 88.8 & 269.7 & 0.095 & 0.010 & 0.085 \\
\hline Z5-S6 & 2.0 & 0.067 & 0.055 & 99.83 & 72.66 & 328.8 & 69.8 & 259.0 & 0.104 & 0.012 & 0.092 \\
\hline Z5-S7 & 3.0 & 0.067 & 0.055 & 93.83 & 73.33 & 326.8 & 75.9 & 250.9 & 0.077 & 0.004 & 0.073 \\
\hline Z5-S8 & 4.0 & 0.067 & 0.028 & 49.88 & 18.33 & 215.3 & 84.6 & 130.7 & 0.101 & 0.016 & 0.045 \\
\hline Z5-S9 & 4.0 & 0.067 & 0.084 & 34.48 & 15.77 & 157.0 & 52.8 & 97.9 & 0.096 & 0.056 & 0.040 \\
\hline Z5-S10 & 4.0 & 0.067 & 0.114 & 29.01 & 19.96 & 166.8 & 70.0 & 96.8 & 0.081 & 0.066 & 0.015 \\
\hline
\end{tabular}

${ }^{a}$ Relative crystallinity from the XRD pattern; ${ }^{b}$ derived from XRF analysis; ${ }^{c}$ Specific surface area obtained from $\mathrm{N}_{2}$ sorption curves; ${ }^{\mathrm{d}}$ Total pore volume obtained by t-plot method.

\subsection{Physicochemical Properties of ZSM-5 Zeolites}

The acid washed fly ash was used as an additive for the synthesis of ZSM-5 zeolites and the single factor experimental conditions are listed in Table 2. The XRD patterns in Figure 4 show that the sodalite phase instead of MFI phase was obtained for S1 when fly ash was used alone as a silicon source and aluminum source. With increasing the TEOS amount as the additional silicon source, the characteristic peaks of ZSM- 5 zeolite at $2 \theta=7.88^{\circ}, 8.76^{\circ}, 23.0^{\circ}, 23.84^{\circ}$, and $24.3^{\circ}$ emerged and their intensity gradually increased, as shown in Figure $4 \mathrm{a}$. The gradual increase of the relative crystallinity of ZSM-5 zeolites with increasing the amount of TEOS in Figure $4 \mathrm{~d}$ indicated that the appropriate $\mathrm{SiO}_{2} / \mathrm{Al}_{2} \mathrm{O}_{3}$ molar ratio was needed for synthesizing $\mathrm{ZSM}-5$ zeolite. In Figure $4 \mathrm{~b}$, with the increase of fly ash amount, the relative crystallinity of ZSM- 5 decreased slightly at first, and greatly decreased to $49.88 \%$ at the fly ash usage of $4 \mathrm{~g}$. In Figure $4 \mathrm{c}$, with the increases the $\mathrm{Na}_{2} \mathrm{O} / \mathrm{SiO}_{2}$ molar ratio, the relative crystallinity of ZSM-5 increased at first and then decreased. The crystallization and dissolution of zeolites were a reversible process, and the high concentration of alkaline solution could inhibit the growth of molecular sieve [23]. As for the $\mathrm{SiO}_{2} / \mathrm{Al}_{2} \mathrm{O}_{3}$ molar ratios derived from the XRF analysis in Table 2, the $\mathrm{SiO}_{2} / \mathrm{Al}_{2} \mathrm{O}_{3}$ molar ratios of $\mathrm{Z5}-\mathrm{S} 5$, Z5-S6, and $\mathrm{Z5}$-S7 were around 72.66 73.33, much higher than that of other samples.

$\mathrm{N}_{2}$ adsorption/desorption isotherms and the pore-size distributions of the as-synthesized ZSM-5 samples are shown in Figure 5. In Figure 5a, the $\mathrm{N}_{2}$ isotherm of Z5-S1 is identified as type II in the Brunauer classification, which is characteristic of nonporous materials, despite small sodalite phase detected in the XRD pattern. It also indicated that most of the glass beads was not converted into porous materials. The isotherms of Z5-Sx $(x=2,3,4,5,6,7,8)$ correspond to type I, which is characteristic of microporous materials. The isotherms of Z5-S9 and Z5-S10 are identified as type I with an H4 hysteresis loop according to the IUPAC classification, indicating the co-presence of micropores and mesopores in the materials $[24,25]$. These mesopores centered at $4 \mathrm{~nm}$ (Figure $5 \mathrm{~b}$ ) presumably arose from the zeolite corrosion by high concentration alkali solution in the synthesizing system. Interestingly, two hysteresis loops for some of the samples are observed. The hysteresis loop at a relative pressure of about 0.2 is small and hardly visible. This hysteresis loop is due to the fact that state variation of adsorbed nitrogen in the micropores of ZSM-5 zeolite: From energetically most favorable positions (like "liquid phase") to the most favorable quadrupole-quadrupole interaction (like "solid phase") with increasing the relative pressure from 0.1 to $0.2[26,27]$. The values of the BET surface area and total pore volume are listed in Table 2. It shows that the variation of the surface area of ZSM-5 samples basically agreed with their relative crystallinities. Amongst, Z5-S5 had the highest BET surface area up to $358.5 \mathrm{~m}^{2} \cdot \mathrm{g}^{-1}$. 

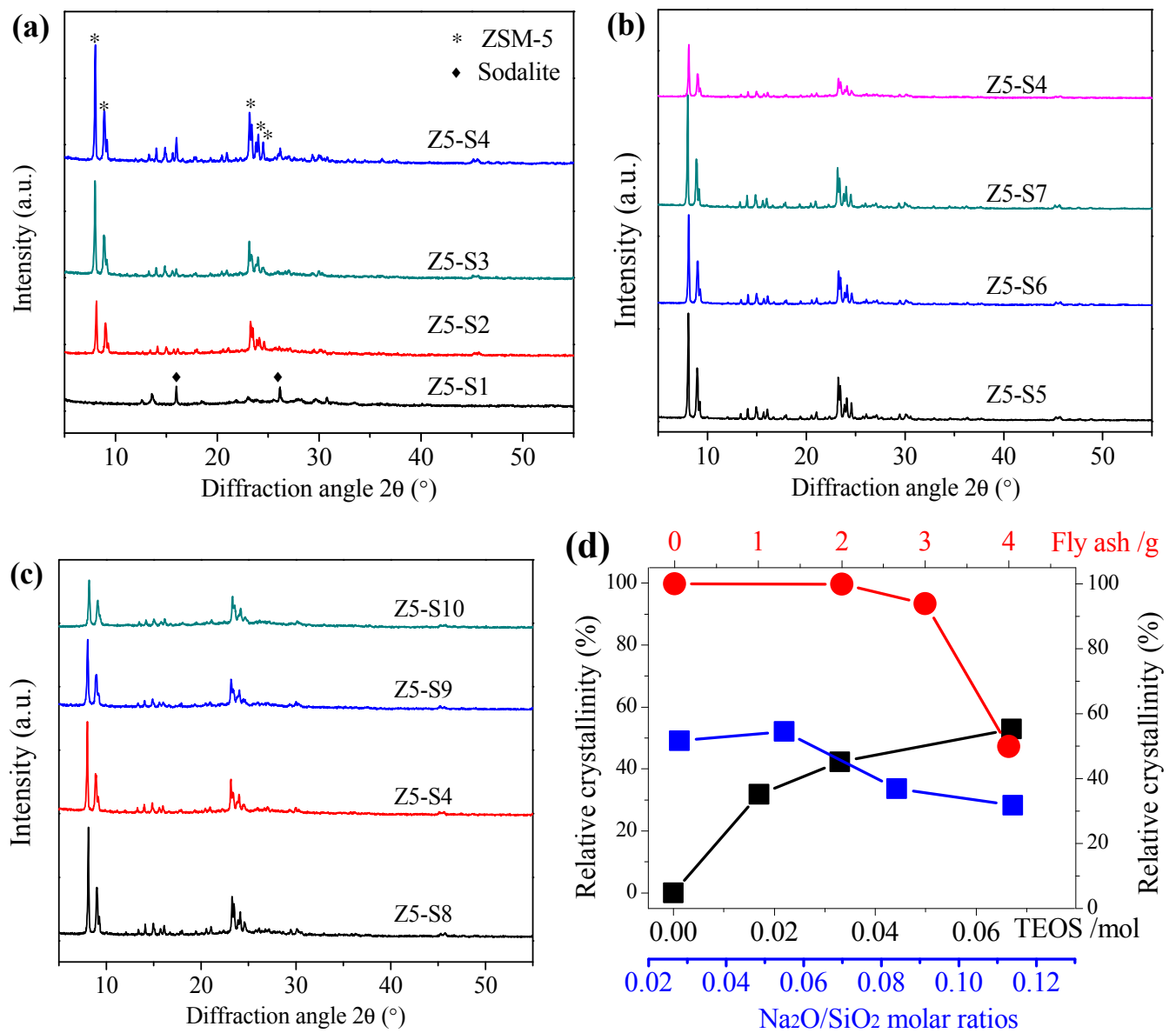

Figure 4. XRD patterns of as-synthesized ZSM-5 zeolites by: (a) Increasing the usage of tetraethyl orthosilicate (TEOS) additive; (b) increasing the usage of fly ash; (c) varying the $\mathrm{Na}_{2} \mathrm{O} / \mathrm{SiO}_{2}$ molar ratios; (d) the change of relative crystallinity of ZSM-5 zeolites with varying the single factor.
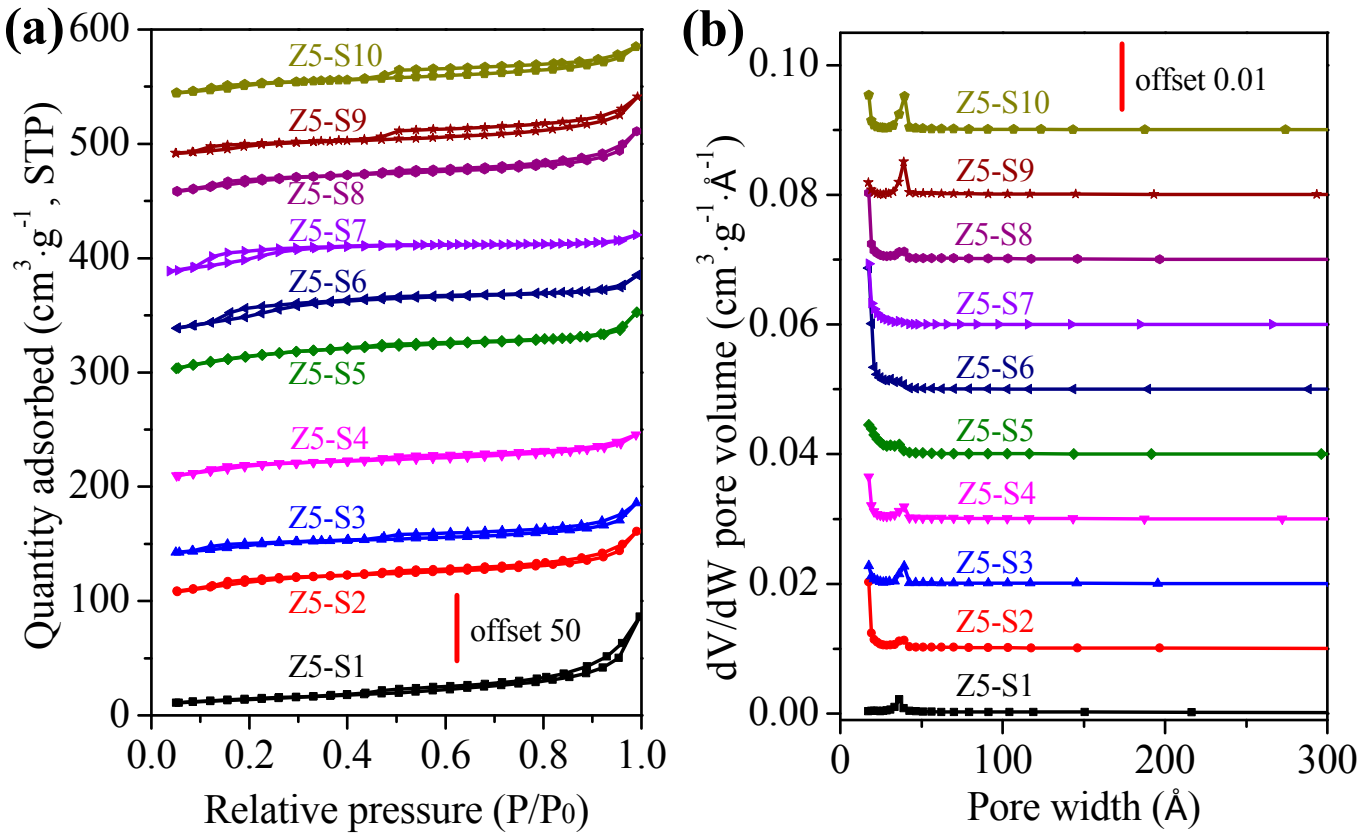

Figure 5. $\mathrm{N}_{2}$ adsorption/desorption isotherms (a) and the pore-size distributions (b) of the as-synthesized samples. 
The SEM imaging in Figure 6a shows that the Z5-S1 consisted of a round particle with rough surface and less than $1 \mu \mathrm{m}$ in diameter, probably due to the partial crystallization of the surface of glass beads (Figure 1). It indicated that the silicon and aluminum sources by alkaline dissolution of the glass beads was not appropriate for the synthesis of ZSM- 5 zeolite, as shown in the XRD pattern. With increasing the amount of TEOS, the newly added silicon source contributed to the formation of ZSM-5 crystalline, in the meantime, the glass beads disappeared. Specifically, the Z5-S3 in Figure 6b possessed cake-like structure with flat exposed (010) lattice plane, having typical diameters of ca. $500 \mathrm{~nm}$ and thick of $400 \mathrm{~nm}$. At high TEOS usage, the Z5-S4 showed a twinned cam morphology (Figure 6c). This means that the amount of TEOS played an important role in accelerating the crystallization of ZSM-5 zeolites. For the Z5-S5 without fly ash addition, the conventional ZSM-5 showed an ellipsoid shaped particle with sizes of 200 400 nm (Figure 6d). The small bulges on the surface of those particles were the aggregates of nanosized ZSM- 5 crystals, indicating that enough silicon source from TEOS contributed to the nucleation in the crystallization process of zeolites. With the addition of fly ash, the round particles ca. $600 \mathrm{~nm}$ with twined crystals emerged for Z5-S6, Z5-S7, and Z5-S8 (Figure 6e-g). With the increase of alkaline concentration, the particles sizes of Z5-S9 and Z5-S10 varied a little (Figure 6h,i). However, the multilayered structure of Z5-S10 particles (Figure 6i) indicated the alkali etching of the surface of ZSM- 5 crystals at high concentration of sodium solution, which should be responsible for the formation of mesopores, as shown in Figure 5.
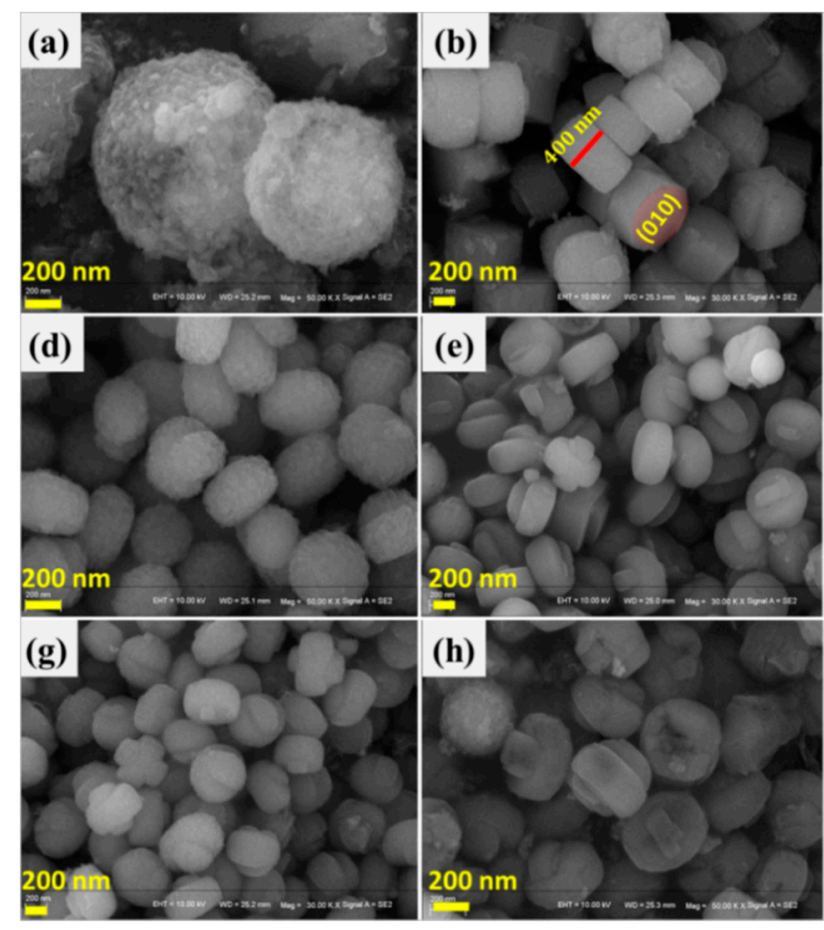
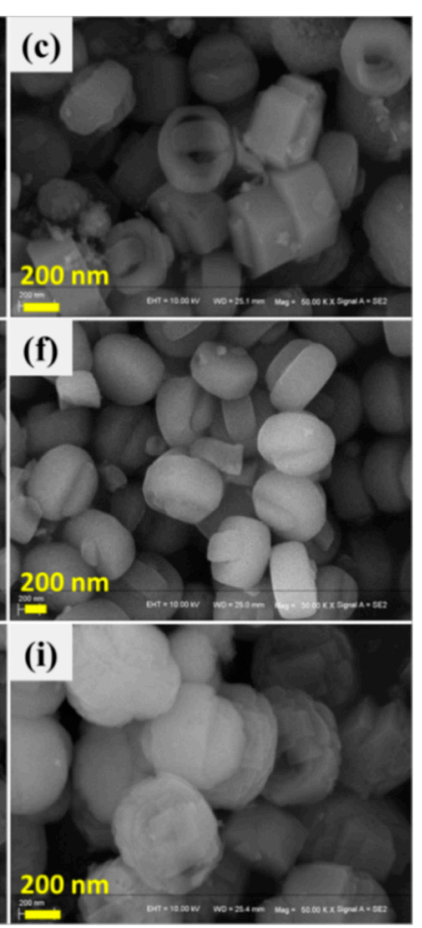

Figure 6. SEM images of the as-synthesized samples: (a) S1; (b) S3; (c) S4; (d) S5; (e) S6; (f) S7; (g) S8; (h) S9; (i) S10.

The strength of accessible acid sites in the selected ZSM-5 catalysts were characterized by $\mathrm{NH}_{3}$-TPD tests. Figure 7a shows a typical acid site distribution as obtained by TPD of ammonia. All samples exhibit three characteristic contributions centered, at ca. $200{ }^{\circ} \mathrm{C}, 400{ }^{\circ} \mathrm{C}$, and $700{ }^{\circ} \mathrm{C}$. The low-temperature profile below $300^{\circ} \mathrm{C}$ corresponds to adsorption on weaker acid sites. The second profile that appears around $300 \sim 500^{\circ} \mathrm{C}$ corresponds to desorption of ammonia from medium strong acid sites. The acid amounts of the catalysts were studied by means of peak differentiating and imitating method and the results are shown in Table 3. It shows that the total acid sites of ZSM-5 catalysts increased with increasing of fly ash usage, mainly due to the increase of weak acid sites; meanwhile, the strong acid sites greatly increased when fly ash was added. The increase of acid sites 
was attributed to the decreased silica-to-alumina ratio on the as-synthesized ZSM-5 catalysts, arising from the introduction of additional aluminium source from fly ash.
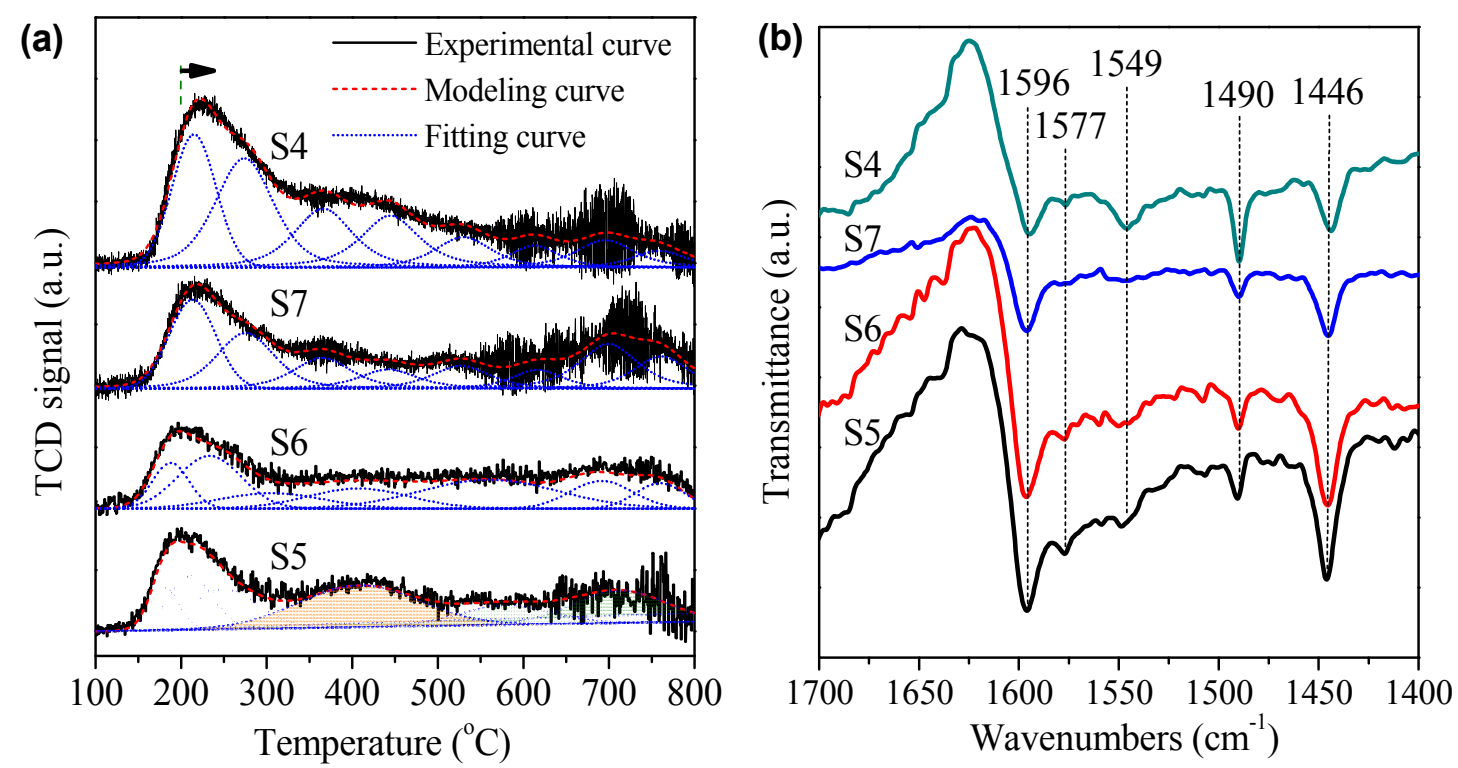

Figure 7. (Brönsted) temperature-programed desorption of ammonia $\left(\mathrm{NH}_{3}\right.$-TPD) curves and (b) pyridine adsorbed FT-IR spectra of selected ZSM-5 samples. Take S5 in Figure 7a for instance, the grey area indicates weak acid, the light orange area indicates medium strong acid, and the light olive area indicates strong acid.

Table 3. Surface acidity of selected ZSM-5 samples derived from the $\mathrm{NH}_{3}$-TPD curves.

\begin{tabular}{|c|c|c|c|c|c|c|c|}
\hline \multirow{2}{*}{ Items } & \multicolumn{4}{|c|}{ Acid Amount $\left(\mu \mathrm{mol} \cdot \mathrm{g}^{-1}\right)^{a}$} & \multicolumn{3}{|c|}{ Acid Amount $\left(\mu \mathrm{mol} \cdot \mathrm{g}^{-1}\right)^{b}$} \\
\hline & Total & Weak $^{c}$ & $\begin{array}{l}\text { Medium } \\
\text { Strong } d\end{array}$ & Strong $\mathrm{e}$ & Total & $\begin{array}{l}\text { Brönsted } \\
\text { Acid Sites }\end{array}$ & $\begin{array}{c}\text { Lewis } \\
\text { Acid Sites }\end{array}$ \\
\hline S5 & 197.4 & 91.7 & 61.1 & 44.6 & 117.8 & 6.5 & 111.3 \\
\hline S6 & 238.6 & 89.8 & 51.4 & 97.4 & 124.9 & 7.5 & 117.4 \\
\hline S7 & 302.9 & 121.4 & 57.2 & 124.3 & 64.4 & 8.9 & 55.5 \\
\hline S4 & 440.5 & 227.1 & 127.9 & 85.5 & 58.8 & 10.8 & 48.0 \\
\hline
\end{tabular}

a acid amount derived from the $\mathrm{NH}_{3}$-TPD tests; ${ }^{\mathrm{b}}$ acid amount derived from pyridine adsorbed FT-IR spectra; ${ }^{c}$ calculated in the temperature below $300{ }^{\circ} \mathrm{C}$; ${ }^{\mathrm{d}}$ calculated in the temperature of $300-500^{\circ} \mathrm{C} ;{ }^{\mathrm{e}}$ calculated in the temperature higher $500^{\circ} \mathrm{C}$.

The acid type was further measured by pyridine adsorbed FT-IR spectra, as shown in Figure $7 \mathrm{~b}$ and Table 3. The bands at $1446 \mathrm{~cm}^{-1}$ and $1549 \mathrm{~cm}^{-1}$ are assigned to the pyridine adsorbed on Lewis acid sites and Brönsted acid sites, respectively [12,28-30]. The bands at $1577 \mathrm{~cm}^{-1}$ and $1596 \mathrm{~cm}^{-1}$ are attributed to the pyridine adsorbed on Lewis acid sites. The band at $1490 \mathrm{~cm}^{-1}$ is generally assigned to the combined Brönsted and Lewis acid sites. The calculated results in Table 3 show that with the increase of fly ash usages, the amount of Brönsted acid sites gradually increased, which might be caused by the insertion of excessive of aluminum atoms in the ZSM-5 zeolites. However, as the crystallinity decreased, the amounts of total acid sites and Lewis acid sites increased slightly at first and then decreased greatly. It indicated that Lewis acid sites, which were found to be the primary source of weak acid sites, were the major acid sites and most of them come from the crystallized zeolites, as previously reported $[29,30]$. Considering the different operating conditions of $\mathrm{NH}_{3}$-TPD and pyridine adsorbed FT-IR analysis, the acid amounts detected were different. 


\subsection{Catalytic Tests of As-Synthesized ZSM-5 Catalysts}

In order to investigate the catalytic activity, four selected catalysts were tested in the conversion of methanol to propylene reaction under the same conditions. Figure 8 represents the lifetimes and selectivities to light olefins in MTP reactions. In general, at the initial stage of reaction, all catalysts exhibited nearly full methanol conversion, indicating the high initial activity of all catalysts. However, with increasing the time on stream, all the tested catalysts gradually reduced their catalytic activity with different deactivation rates (in Figure 8a), which could be ascribed to the coverage of acid sites and/or pore blockage by coke species, based on the previous reports [12,31,32]. Hereafter, the catalyst lifetime was defined as the time for which the conversion of methanol exceeded $85 \%$. It clearly shows that the lifetimes of the catalysts decreased with increasing the fly ash usages, being mainly attributed to the increased amounts of acid sites, especially the strong acid sites (as shown Table 3).
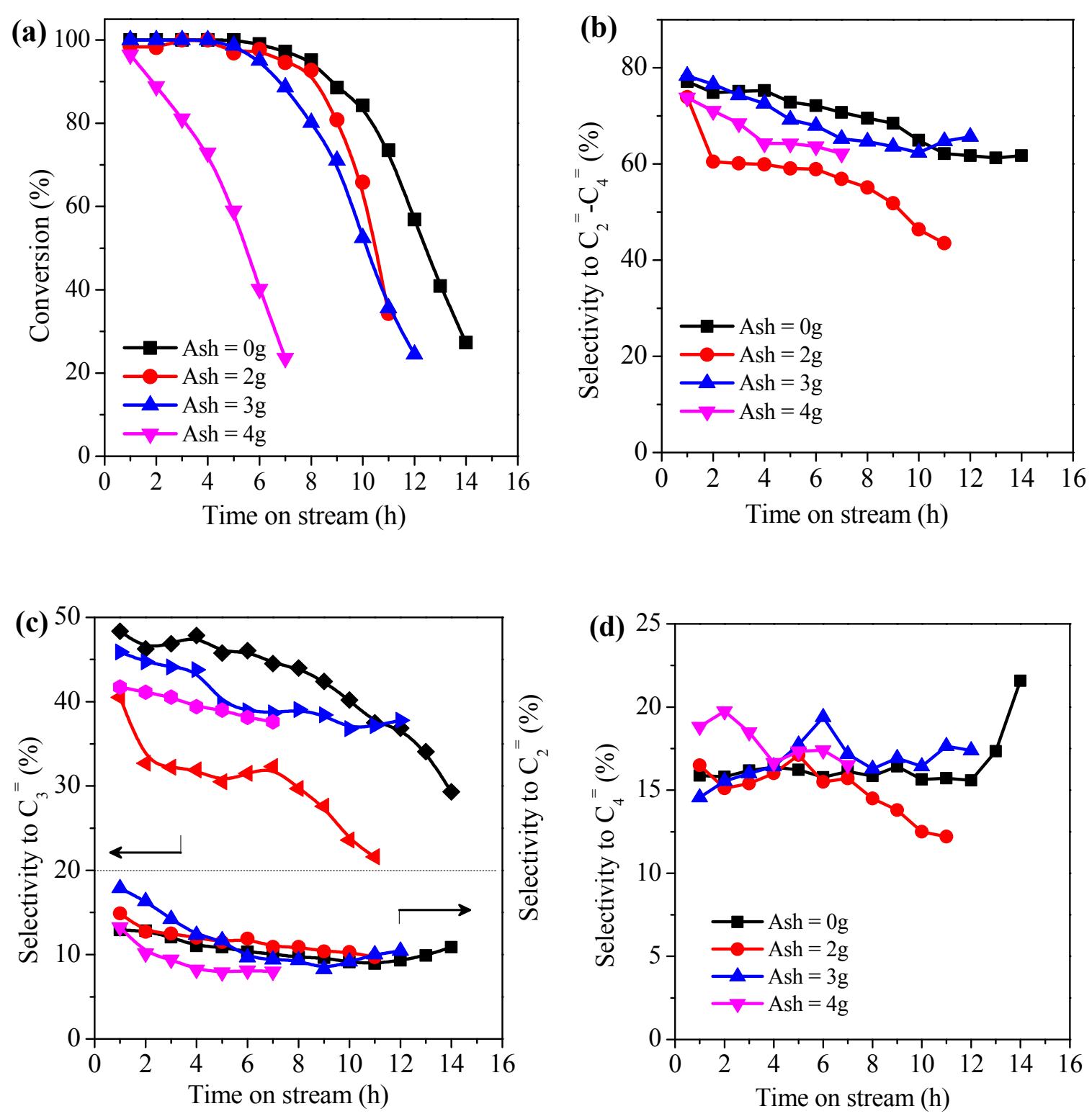

Figure 8. Methanol to propylene (MTP) reaction performances of selected catalysts with increasing the amount of fly ash, corresponding to S5, S6, S7, and S4, respectively. (a) Methanol conversion; (b) selectivity to $C_{2}=-C_{4}=;\left(\right.$ c) selectivity to $C_{3}=$ and $C_{2}=;(d)$ selectivity to $C_{4}=$. Conditions: $0.10 \mathrm{~g}$ catalyst, $\mathrm{T}=470{ }^{\circ} \mathrm{C}$, atmospheric pressure, weight hourly space velocity (WHSV) of methanol $=4.0 \mathrm{~h}^{-1}$. 
The product distributions of four catalysts at time on stream of $4 \mathrm{~h}$ are shown in Figure 9. The selectivity to propylene for S5 without fly ash addition was the highest, up to $47.85 \%$. With increasing the fly ash usage, the selectivities to ethylene and propylene of the as-synthesized catalysts decreased, in contrast, the selectivities to $\mathrm{C}_{5}+$ products increased. In the recently proposed "dual cycle" mechanism to explain the formation of ethylene and propylene, propylene and ethylene could be generated by the aromatic-based cycle, whereas, propylene mainly produced by the olefin-based cycle [33,34]. In this work, the propylene to ethylene ratio of selected samples were similar and in the scope of 3.6-4.7, indicating the primary pathway through the olefin-based cycle. However, intermediates like $\mathrm{C}_{5}+$ molecules, which undergoes successive methylation steps on acid sites by methanol and subsequently eliminates light olefins, are likely to be essential for the formation of propylene [35]. On the other hand, the most often observed $\mathrm{C}_{5}+$ intermediates to date have been typically methylbenzenes [36]. Those easily adsorb on the strong acid sites and/or block the pore mouth, leading to the fast deactivation, as shown in Figure 8. Therefore, excessive amounts of acid sites, especially strong acid sites, is disadvantageous on catalytic lifetime. Technically, the optimal silicon and aluminum sources in the synthesizing system, is very desirable for the fine control of acidity on the ZSM- 5 catalysts.

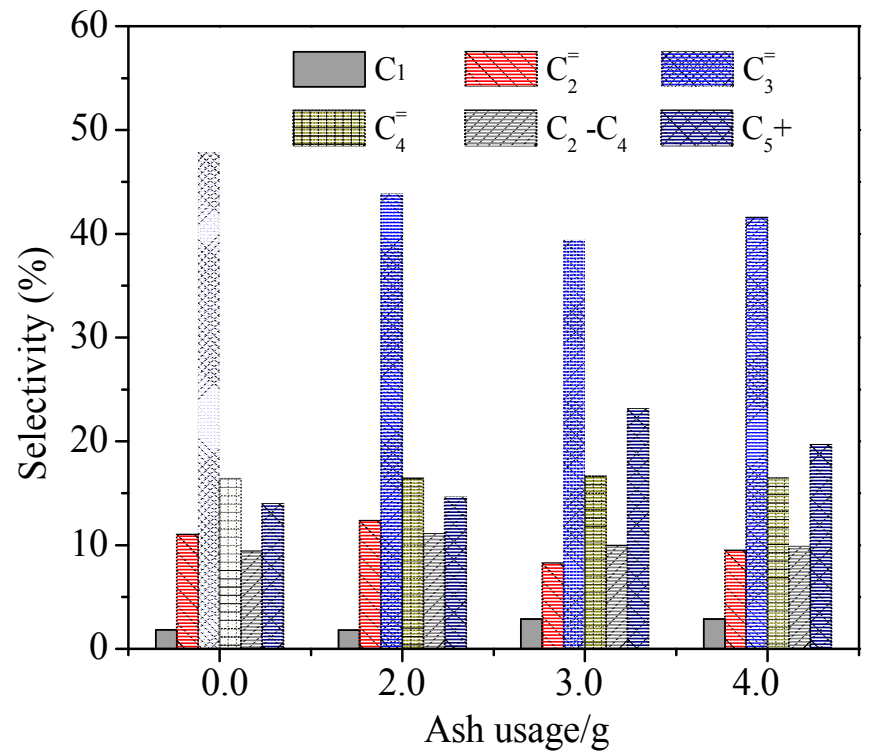

Figure 9. Products selectivities for four selected catalysts at the time-on-stream of $4 \mathrm{~h}$.

\section{Experimental Section}

\subsection{Raw Materials}

Coal based fly ash was supplied by Tian-xi Coal-to-Oil branch of Shanxi Jincheng Coal Industry Group Ltd. (Shanxi, China) and its properties is listed in Table 1. Nitric acid $\left(\mathrm{HNO}_{3}\right)$, sodium hydroxide $(\mathrm{NaOH})$, and tetraethyl orthosilicate (TEOS) with analytical purity were purchased from Sinopharm Reagent Co. Ltd. (Shanghai, China). Tetrapropyl ammonium hydroxide (TPAOH) of $25 \mathrm{wt} \%$ aqueous solution was also purchased from Sinopharm Reagent Co. Ltd. (Shanghai, China).

\subsection{Materials Synthesis}

The fly ash was first pretreated by the acid washing method. Typically, $30 \mathrm{~g}$ fly ash was mixed with $2 \mathrm{M}$ of $\mathrm{HNO}_{3}$ solution at $90^{\circ} \mathrm{C}$ for $2 \mathrm{~h}$ under stirring. The solid was filtered and washed with deionized water. Sample powder was dried at $110^{\circ} \mathrm{C}$ for overnight.

The ZSM-5 zeolites were synthesized by the conventional hydrothermal crystallization method, similar to that previously reported [12]. Typically, the pretreated fly ash was mixed with sodium hydroxide, 
TPAOH, deionized water, and TEOS and stirred at room temperature for $12 \mathrm{~h}$. Then, the mixture was transferred into a Teflon-lined stainless autoclave for crystallization at $170{ }^{\circ} \mathrm{C}$ for $48 \mathrm{~h}$. Here, the final gel compositions of synthesizing system were $x \mathrm{SiO}_{2}: y \mathrm{Na}_{2} \mathrm{O}: 1.0 \mathrm{Al}_{2} \mathrm{O}_{3}: 8 \mathrm{TPAOH}: 3000 \mathrm{H}_{2} \mathrm{O}$. Here, the $x$ and $y$ were adjusted by changing the usage of the pretreated fly ash, TEOS and $\mathrm{NaOH}$, using the single factor experiment method. The details were listed in Table 2. After crystallization, the solid was obtained by filtering, washing and drying. The above Na-form ZSM- 5 was transformed into the H-form ZSM- 5 after twice ion-exchange with $1.0 \mathrm{~mol} / \mathrm{L}$ of $\mathrm{NH}_{4} \mathrm{Cl}$ solution and once calcination at $550{ }^{\circ} \mathrm{C}$ for $4 \mathrm{~h}$.

\subsection{Characterization}

The crystalline phases were determined by the X-ray diffraction (XRD) analysis on a Bruker D8 Advance Diffractometer (Bruker, Billerica, MA, USA) with Cu-K $\alpha$ radiation $(\lambda=0.15406 \mathrm{~nm})$, operating at $40 \mathrm{kV}$ and $30 \mathrm{~mA}$ and scanning from $5^{\circ}$ to $60^{\circ}$ at a speed of $0.02 \%$. Five main characteristic peaks of MFI zeolites were selected to calculate their relative crystallinities. Nitrogen sorption measurements were performed on a Micrometrics TriStar3000 analyser (Micromeritics, Norcross, GA, USA) at $-196^{\circ} \mathrm{C}$ to characterize the textural property. All samples were pre-treated at $300^{\circ} \mathrm{C}$ and vacuum for $3 \mathrm{~h}$ before the measurement. The Brunauer-Emmett-Teller (BET) method and $\mathrm{BJH}$ method were respectively used to determine the surface areas and pore volumes. The silica-to-alumina ratio $\left(\mathrm{SiO}_{2} / \mathrm{Al}_{2} \mathrm{O}_{3}\right)$ was detected by the inductively coupled plasma optical emission spectrometry (ICP-OES) method. Field emission scanning electron microscopy (SEM) images were taken on a Quanta250 instrument (Hillsboro, OR, USA). The acid distribution was measured by temperature-programed desorption of ammonia ( $\mathrm{NH}_{3}-\mathrm{TPD}$ ) on a Quanta Chrome ChemStar ${ }^{\mathrm{TM}}$ instrument (Boynton Beach, FL, USA). The acid properties of ZSM-5 samples were detected on a Nicolet iS5 Fourier transform infrared (FTIR) spectrometer (Waltham, MA, USA) using pyridine as a probe molecule. Each spectrum was recorded by a total of 64 scans with a resolution of $4 \mathrm{~cm}^{-1}$. The acid amounts were obtained from infrared transmittance spectroscopy, according to the previous report by Emeis. [37] The acid amount of pyridine per gram catalyst $(\mathrm{C})$ was obtained by the Equation as follows.

$$
C \text { (pyridine on acid sites, } \mathrm{mmol} / \mathrm{g} \text { catalyst })=k I R^{2} / \mathrm{W}
$$

where $k$ is the integrated molar extinction coefficient of pyridine on Brönsted (at ca. $1540 \mathrm{~cm}^{-1}$, $1.67 \mathrm{~cm} / \mu \mathrm{mol}$ ) or Lewis acid sites (at ca. $1450 \mathrm{~cm}^{-1}, 2.22 \mathrm{~cm} / \mu \mathrm{mol}$ ), I is the integrated absorbance $\left(\mathrm{cm}^{-1}\right)$, $\mathrm{R}$ is the radius of catalyst disk on the FT-IR instrument $(\mathrm{cm}), \mathrm{W}$ is the weight of catalyst disk $(\mathrm{mg})$.

\subsection{Catalytic Tests}

The methanol to propylene (MTP) reaction was performed on a fixed bed reactor at atmospheric pressure, similar to the previously reported by us [32,38,39]. Pure ZSM- 5 catalysts with particle sizes of 40-60 mesh were prepared by pressing, crushing, and sieving. A quartz tubular reactor with $6 \mathrm{~mm}$ of inner diameter was placed into the furnace, using $0.10 \mathrm{~g}$ of catalyst. The catalyst was pretreated at $500^{\circ} \mathrm{C}$ for $1 \mathrm{~h}$ in argon flow gas before the reaction. The temperature for MTP reaction was set to $470^{\circ} \mathrm{C}$ and methanol was injected into the reactor using $50 \mathrm{~mL} / \mathrm{min}$ of argon as carrier gas. The weight hourly space velocity (WHSV) of methanol was set to $4.0 \mathrm{~h}^{-1}$. The coke contents on spent catalysts were determined by the elemental analysis on Elementar Various EL Cube analyzer. The reaction products were analyzed using an online gas chromatograph (GC 2014C, Shimadzu GC) with a TG-BONG $\mathrm{Q}$ column $(30 \mathrm{~m} \times 0.32 \mathrm{~mm} \times 10 \mu \mathrm{m})$. Equipped thermal conductivity detector (TCD) and flame ionization detector (FID) were used to measure the products of $\mathrm{CH}_{4}, \mathrm{CH}_{3} \mathrm{OH}$, dimethyl ether (DME), and other hydrocarbon products, operating at the oven temperature of $50-180{ }^{\circ} \mathrm{C}$ and a heating ramp of $10^{\circ} \mathrm{C} / \mathrm{min}$. The methanol conversion was defined as usual:

$$
X_{\mathrm{MeOH}}=\frac{\left(m_{\mathrm{MeOH}(\text { in })}-1.39 m_{\mathrm{DME}(\text { out })}-m_{\mathrm{MeOH}(\text { out })}\right)}{m_{\mathrm{MeOH}(\text { in })}}
$$


While selectivity to the $i$ product was defined as follows:

$$
S_{i}=\frac{m_{i}}{\Sigma m_{i}}
$$

where $m_{i}$ is the mass weight of compound $i$, and $\Sigma m_{i}$ is the total mass weight of all products. In the products, DME was found when methanol conversion decreased with time on stream and one DME molecule was regarded as two molecules of unconverted methanol. The mass balance was carefully controlled with an average error below $3 \%$.

\section{Conclusions}

In this study, ZSM-5 zeolites for the MTP reaction were synthesized by the conventional hydrothermal crystallization method using fly ash as additional silicon and aluminum sources. The characterization results demonstrated that the presence of tetraethyl orthosilicate (TEOS) is necessary for the crystallization of ZSM- 5 zeolites. With increasing the usage amounts of fly ash, the total amount of acid sites of ZSM- 5 zeolites detected by the $\mathrm{NH}_{3}$-TPD method gradually increased, due to a large amount of weak Lewis acid sites and a bit of strong Brönsted acid sites. However, the MTP reaction propylene selectivity and the catalytic lifetime of ZSM-5 decreased due to the increased amount of acid sites, especially the strong acid sites. In the coming work, the sufficient and effective use of the silicon and aluminum sources in fly ash is meaningful, and the effects of the impurities in fly ash on the crystallization of zeolites and their acid properties will be considered.

Author Contributions: R.F. and X.H. wrote the main manuscript text; Investigation and analysis, K.C. and Y.Z.; Review and editing X.Y. and J.W. All authors reviewed the manuscript.

Funding: This research was funded by the Fundamental Research Funds for the Central Universities (Grant No. 2018QNB04) and the Priority Academic Program Development of Jiangsu Higher Education Institutions.

Conflicts of Interest: The authors declare no conflict of interest.

\section{References}

1. Belviso, C. State-of-the-art applications of fly ash from coal and biomass: A focus on zeolite synthesis processes and issues. Prog. Energy Combust. Sci. 2018, 65, 109-135. [CrossRef]

2. Koukouzas, N.K.; Zeng, R.; Perdikatsis, V.; Xu, W.; Kakaras, E.K. Mineralogy and geochemistry of Greek and Chinese coal fly ash. Fuel 2006, 85, 2301-2309. [CrossRef]

3. Ahmaruzzaman, M. A review on the utilization of fly ash. Prog. Energy Combust. Sci. 2010, 36, $327-363$. [CrossRef]

4. Vogt, E.T.C.; Weckhuysen, B.M. Fluid catalytic cracking: Recent developments on the grand old lady of zeolite catalysis. Chem. Soc. Rev. 2015, 44, 7342-7370. [CrossRef]

5. Feng, R.; Qiao, K.; Wang, Y.-h.; Yan, Z.-f. Perspective on FCC catalyst in China. Appl. Petrochem. Res. 2013, 3, 63-70. [CrossRef]

6. Weckhuysen, B.M.; Yu, J. Recent advances in zeolite chemistry and catalysis. Chem. Soc. Rev. 2015, 44, 7022-7024. [CrossRef]

7. Thomas, J.M.; Raja, R.; Lewis, D.W. Single-Site Heterogeneous Catalysts. Angew. Chem. Int. Ed. 2005, 44, 6456-6482. [CrossRef]

8. Procopio, A.; Cravotto, G.; Oliverio, M.; Costanzo, P.; Nardi, M.; Paonessa, R. An eco-sustainable erbium(iii)-catalyzed method for formation/cleavage of O-tert-butoxy carbonates. Green Chem. 2011, 13, 436-443. [CrossRef]

9. Procopio, A.; De Luca, G.; Nardi, M.; Oliverio, M.; Paonessa, R. General MW-assisted grafting of MCM-41: Study of the dependence on time dielectric heating and solvent. Green Chem. 2009, 11, 770-773. [CrossRef]

10. Wang, F.-F.; Wu, H.-Z.; Ren, H.-F.; Liu, C.-L.; Xu, C.-L.; Dong, W.-S. Er/ $\beta$-zeolite-catalyzed one-pot conversion of cellulose to lactic acid. J. Porous Mater. 2017, 24, 697-706. [CrossRef] 
11. Ballini, R.; Boscia, G.; Carloni, S.; Ciaralli, L.; Maggi, R.; Sartori, G. Zeolite HSZ-360 as a new reusable catalyst for the direct acetylation of alcohols and phenols under solventless conditions. Tetrahedron Lett. 1998, 39, 6049-6052. [CrossRef]

12. Feng, R.; Wang, X.; Lin, J.; Li, Z.; Hou, K.; Yan, X.; Hu, X.; Yan, Z.; Rood, M.J. Two-stage glucose-assisted crystallization of ZSM-5 to improve methanol to propylene (MTP). Microporous Microporous Mater. 2017, 270, 57-66. [CrossRef]

13. Losch, P.; Pinar, A.B.; Willinger, M.G.; Soukup, K.; Chavan, S.; Vincent, B.; Pale, P.; Louis, B. H-ZSM-5 zeolite model crystals: Structure-diffusion-activity relationship in methanol-to-olefins catalysis. J. Catal. 2017, 345, 11-23. [CrossRef]

14. Xue, T.; Li, S.; Wu, H.; Wu, P.; He, M. Eco-friendly and cost-effective synthesis of ZSM-5 aggregates with hierarchical porosity. Ind. Eng. Chem. Res. 2017, 56, 13535-13542. [CrossRef]

15. Ojumu, T.V.; Du Plessis, P.W.; Petrik, L.F. Synthesis of zeolite A from coal fly ash using ultrasonic treatment-A replacement for fusion step. Ultrason. Sonochem. 2016, 31, 342-349. [CrossRef]

16. Srinivasan, A.; Grutzeck, M.W. The adsorption of $\mathrm{SO}_{2}$ by zeolites synthesized from fly ash. Environ. Sci. Technol. 1999, 33, 1464-1469. [CrossRef]

17. Cardoso, A.M.; Horn, M.B.; Ferret, L.S.; Azevedo, C.M.N.; Pires, M. Integrated synthesis of zeolites 4A and $\mathrm{Na}-\mathrm{P} 1 \mathrm{using}$ coal fly ash for application in the formulation of detergents and swine wastewater treatment. J. Hazard. Mater. 2015, 287, 69-77. [CrossRef]

18. Chen, Y.; Cong, S.; Wang, Q.; Han, H.; Lu, J.; Kang, Y.; Kang, W.; Wang, H.; Han, S.; Song, H.; et al. Optimization of crystal growth of sub-micron ZSM-5 zeolite prepared by using $\mathrm{Al}(\mathrm{OH})_{3}$ extracted from fly ash as an aluminum source. J. Hazard. Mater. 2018, 349, 18-26. [CrossRef]

19. Soongprasit, K.; Sricharoenchaikul, V.; Atong, D. Pyrolysis of Millettia (Pongamia) pinnata waste for bio-oil production using a fly ash derived ZSM-5 catalyst. J. Anal. Appl. Pyrolysis 2019, 139, 239-249. [CrossRef]

20. Vichaphund, S.; Wimuktiwan, P.; Sricharoenchaikul, V.; Atong, D. In situ catalytic pyrolysis of Jatropha wastes using ZSM-5 from hydrothermal alkaline fusion of fly ash. J. Anal. Appl. Pyrolysis 2019, 139, 156-166. [CrossRef]

21. Wu, H.; Zhang, Y.; Ren, Q.; Wang, Y.; Lyu, Q. Impact of residual carbon on ash fusibility of semi-char from an industrial circulating fluidized bed gasifier. Energy Fuel 2019, 33, 531-540. [CrossRef]

22. Li, F.; Liu, Q.; Li, M.; Fang, Y. Understanding fly-ash formation during fluidized-bed gasification of high-silicon-aluminum coal based on its characteristics. Energy 2018, 150, 142-152. [CrossRef]

23. Zhou, J.; Teng, J.; Ren, L.; Wang, Y.; Liu, Z.; Liu, W.; Yang, W.; Xie, Z. Full-crystalline hierarchical monolithic ZSM-5 zeolites as superiorly active and long-lived practical catalysts in methanol-to-hydrocarbons reaction. J. Catal. 2016, 340, 166-176. [CrossRef]

24. Sotomayor, F.J.; Cychosz, K.A.; Thommes, M. Characterization of micro/mesoporous materials by physisorption: Concepts and case studies. Acc. Mater. Surf. Res. 2018, 3, 34-50.

25. Thommes, M.; Kaneko, K.; Neimark, A.V.; Olivier, J.P.; Rodriguez-Reinoso, F.; Rouquerol, J.; Sing, K.S. Physisorption of gases, with special reference to the evaluation of surface area and pore size distribution (IUPAC Technical Report). Pure Appl. Chem. 2015, 87, 1051-1069. [CrossRef]

26. Janssen, A.H.; Schmidt, I.; Jacobsen, C.J.H.; Koster, A.J.; de Jong, K.P. Exploratory study of mesopore templating with carbon during zeolite synthesis. Microporous Microporous Mater. 2003, 65, 59-75. [CrossRef]

27. Groen, J.C.; Pérez-Ramírez, J. Critical appraisal of mesopore characterization by adsorption analysis. Appl. Catal. A 2004, 268, 121-125. [CrossRef]

28. Feng, R.; Hu, X.; Yan, X.; Yan, Z.; Rood, M.J. A high surface area mesoporous $\gamma-\mathrm{Al}_{2} \mathrm{O}_{3}$ with tailoring texture by glucose template for ethanol dehydration to ethylene. Microporous Microporous Mater. 2017, 241, 89-97. [CrossRef]

29. Feng, R.; Liu, S.; Bai, P.; Qiao, K.; Wang, Y.; Al-Megren, H.A.; Rood, M.J.; Yan, Z. Preparation and Characterization of $\gamma-\mathrm{Al}_{2} \mathrm{O}_{3}$ with rich Brönsted acid sites and its application in the fluid catalytic cracking process. J. Phys. Chem. C 2014, 118, 6226-6234. [CrossRef]

30. Feng, R.; Yan, X.; Hu, X.; Qiao, K.; Yan, Z.; Rood, M.J. High performance of $\mathrm{H}_{3} \mathrm{BO}_{3}$ modified USY and equilibrium catalyst with tailored acid sites in catalytic cracking. Microporous Microporous Mater. 2017, 243, 319-330. [CrossRef]

31. Wan, Z.; Li, G.K.; Wang, C.; Yang, H.; Zhang, D. Relating coke formation and characteristics to deactivation of ZSM-5 zeolite in methanol to gasoline conversion. Appl. Catal. A 2018, 549, 141-151. [CrossRef] 
32. Feng, R.; Yan, X.; Hu, X.; Yan, Z.; Lin, J.; Li, Z.; Hou, K.; Rood, M.J. Surface dealumination of micro-sized ZSM-5 for improving propylene selectivity and catalyst lifetime in methanol to propylene (MTP) reaction. Catal. Commun. 2018, 109, 1-5. [CrossRef]

33. Arora, S.S.; Bhan, A. The critical role of methanol pressure in controlling its transfer dehydrogenation and the corresponding effect on propylene-to-ethylene ratio during methanol-to-hydrocarbons catalysis on H-ZSM-5. J. Catal. 2017, 356, 300-306. [CrossRef]

34. Tian, P.; Wei, Y.; Ye, M.; Liu, Z. Methanol to olefins (MTO): From fundamentals to commercialization. ACS Catal. 2015, 5, 1922-1938. [CrossRef]

35. Vandichel, M.; Lesthaeghe, D.; Van der Mynsbrugge, J.; Waroquier, M.; Van Speybroeck, V. Assembly of cyclic hydrocarbons from ethene and propene in acid zeolite catalysis to produce active catalytic sites for MTO conversion. J. Catal. 2010, 271, 67-78. [CrossRef]

36. An, H.; Zhang, F.; Guan, Z.; Liu, X.; Fan, F.; Li, C. Investigating the coke formation mechanism of H-ZSM-5 during methanol dehydration using operando UV-Raman spectroscopy. ACS Catal. 2018, 8, 9207-9215. [CrossRef]

37. Emeis, C.A. Determination of integrated molar extinction coefficients for infrared absorption bands of pyridine adsorbed on solid acid catalysts. J. Catal. 1993, 141, 347-354. [CrossRef]

38. Feng, R.; Yan, X.; Hu, X.; Wang, Y.; Li, Z.; Hou, K.; Lin, J. Hierarchical ZSM-5 zeolite designed by combining desilication and dealumination with related study of n-heptane cracking performance. J. Porous Mater. 2018, 25, 1743-1756. [CrossRef]

39. Jiang, L.; Li, C.; Xu, M.; Xing, A.; Feng, R.; Wu, J. Investigation on and industrial application of degrading of methanol feed in methanol to propylene process. Chin. J. Chem. Eng. 2018, 26, 2102-2111. [CrossRef]

(C) 2019 by the authors. Licensee MDPI, Basel, Switzerland. This article is an open access article distributed under the terms and conditions of the Creative Commons Attribution (CC BY) license (http://creativecommons.org/licenses/by/4.0/). 